\title{
LA CORPORALIDAD EN LA ESCENA CONTEMPORÁNEA
}

\author{
María José Sánchez Montes \\ Univesidad de Granada \\ mariaj@ugr.es
}

Antonin Artaud se pregunta en El teatro y su doble si acaso el ámbito concreto de la escena teatral no es un espacio físico donde el cuerpo, en lugar de la palabra y la psicología, aparece como el medio más preciso para alcanzar sus objetivos (Artaud, 1986: 80). Con esta pregunta, en la que se oculta una afirmación, Artaud da forma a unos planteamientos que, desde finales del siglo XIX, habían venido ocupando a aquellos que se dedicaban al mundo de la escena en su vertiente práctica.

La necesidad de dejar constancia teórica de unos planteamientos provenientes de la práctica escénica trae consigo un giro fudamental en el modo de entender la escena a lo largo del siglo XX. En estas páginas nos vamos a ocupar de la gestación de la idea recogida por Artaud que se circunscribe al proceso concreto de revalorización que, desde finales del siglo XIX, había venido experimentando el cuerpo escénico, el cuerpo del actor. Este proceso se fundamenta definitiva- 
mente en los textos teóricos y en las prácticas teatrales de un conjunto escogido de personalidades de la escena del primer tercio del siglo $\mathrm{XX}$, entre las que vamos a destacar a Adolphe Appia, Edward Gordon Craig, Constantin Stanislavski y Vsevolod Meyerhold.

A pesar de que nos centremos en el siglo XX como momento trascendental para una transformación - es decir, un cambio en la mirada y en los planteamientos generales de los distintos ámbitos considerados artísticos- y en el caso concreto de la escena, a un intento por parte de la teoría y la práctica teatral de tender hacia un tipo de espectáculo que se aproximase al concepto de teatro como un todo, tal afirmación no puede hacerse extensiva a todo el teatro que se produce en el siglo XX. Muy al contrario, la escena teatral aún en estos primeros años del siglo XXI sigue estando habitada, cuando menos parcialmente, por un tipo de espectáculo que todavía tiene mucho que ver con el realismo, así como con formas decimonónicas y burguesas de puesta en escena.

Como sabemos, a causa de la creencia de que el teatro está fundamentalmente constituido por la puesta en escena de un texto previo al espectáculo que además adquiere la consideración de literario, el desarrollo de la historia del teatro se ha llevado a cabo preferentemente desde los textos dramáticos, lo que en muchos casos ha dado como resultado una historia sesgada de los hechos acontecidos en el ámbito escénico. En numerosas ocasiones lo que realmente se llega a ver, o se ha visto, en los escenarios teatrales no se corresponde con lo que las historias del teatro tradicionalmente nos han venido contando, por seguir éstas mayoritariamente la periodización aplicada a los textos denominados literarios, entre los cuales los dramáticos quedan por lo general incluidos. Se hace necesario, entonces, poner de manifiesto que aunque efectivamente, como señalan Grande Rosales y Sánchez Trigueros, «una episteme de la teoría teatral del siglo XX debe trazarse, sin lugar a dudas, desde el cuerpo» (Grande Rosales y Sánchez Trigueros, 1996: 263), la situación en la que aún se encuentran muchos de nuestros teatros, tras un siglo de intentos por abandonar las formas tradicionales de aproximación al espectáculo teatral, se inserta en un debate que se alarga más de cien años y que no nos permite, al menos de manera general y por ello no sin cierto atisbo de provocación cuando lo hacemos, referimos a la práctica teatral como práctica corporal generalizada.

La cuestión en torno a la primacía del cuerpo, concretamente en lo que concierne al ámbito de la escena teatral, no surge de manera ais- 
lada, sino que se enmarca dentro de un problema mucho más ámplio que va a afectar no sólo al teatro sino, en general, a todos los lenguajes artísticos. Efectivamente, el lenguaje en su faceta lingüística, comunicativa y racional, así como en su conexión con las formas realistas de expresión artística —como va a poner de manifiesto Ortega y Gasset en su ensayo La deshumanización del arte-, se ve inmerso a finales del siglo XIX en una crisis motivada por una incapacidad comunicativa manifiesta que, a su vez, da paso a una reflexión sobre los medios que entran en juego en la propia producción artística y que, en el caso concreto de la escena teatral, se traduce en una reflexión sobre la escena desde la propia escena. El teatro, por tanto, acusa la pérdida de la fe en la palabra que a su vez, a partir del último tercio del siglo XIX y en concreto a partir de las teorías wagnerianas, deriva en la puesta en cuestión de la confianza depositada en ella. En ese sentido, podemos entonces afirmar que los primeros atisbos de posibilidad de concepción del espectáculo teatral, como síntesis de todas las artes, desencadenan a su vez toda una redefinición del arte teatral. Este replanteamiento supone el cuestionamiento, en primer lugar, del carácter logocéntrico del lenguaje de la escena, así como de la propia creencia en que su universo haya de ser fundamentalmente realista y su comprensión racional, por lo que se comienza, a su vez, a considerar que es posible la acción teatral a través de unos medios expresivos que le sean propios. El fenómeno, sin embargo, tendrá un efecto diferente al que se produce concretamente en los textos, puesto que prescindir de la palabra o silenciarla en el ámbito escénico como ocurre en muchos casos - no significa necesariamente acabar con el espectáculo teatral, sino que, muy al contrario, contribuye a poner de manifiesto la contingencia de su presencia en la misma e implica potenciar posibilidades nuevas para la escena, además de una significativa apertura de la misma a todo un renovado impulso para otros sistemas de signos. En ese sentido, por tanto, podemos referirnos a una cierta inversión del lugar de la palabra, así como a una revalorización del papel del cuerpo en el ámbito de la escena teatral en virtud de la cual se entiende que éste no ha de atenerse al oficio de desempeñar simplemente el papel de mero sustento de la palabra dramática. De ese modo, como señala Sánchez, el centro de interés se traslada desde la comprensión del hecho teatral como manifestación del drama a entender éste como elemento subsidiario de la dimensión espectacular (Sánchez, 1999: 20).

Las teorías de Richard Wagner sirven de impulso para el desarrollo de un modo de pensar el fenómeno teatral que, por un lado, comparte 
ciertos vínculos con el Romanticismo ${ }^{1}$ pero por otro constituye también una senda abierta hacia la puesta en cuestión del lugar de la palabra en el espectáculo teatral, a la que ya nos hemos referido ${ }^{2}$. A consecuencia de esta relocalización del texto en la escena se origina una tendencia que a su vez, conduce a una nueva mirada hacia el cuerpo del actor así como a la revalorización de su papel en la misma.

En ese sentido las teorías sobre la escena de Adolphe Appia, Edward Gordon Craig, Constantin Stanislavski y Vsevolod Meyerhold pueden ser consideradas artífices de los fundamentos de esta tendencia. En general, podemos afirmar que los cuatro teóricos del teatro que nos ocupan se encuentran, o bien de alguna manera vinculados directamente al músico y teórico alemán, o cuando menos relacionados con sus teorías, por cuanto éstas son tenidas en cuenta aún en el caso en el que su operatividad sea cuestionada. Incluso cuando lo único que se lleva a cabo es una valoración un tanto negativa de ellas, podemos decir que su aparición como referente contribuye a afianzar la idea de escena que desarrolla cada uno de ellos.

Adolphe Appia es, sin lugar a dudas, el que guarda un vínculo más directo con el músico alemán, debido a que precisamente su preocupación y primeros planteamientos sobre el espectáculo teatral provienen directamente de un deseo de llevar a la práctica las teorías wagnerianas en puestas en escena de las propias óperas de Wagner. No obstante, más allá de los espectáculos concretos, las ideas del músico alemán sirven al teórico suizo de impulso - no sin dejar de cuestionar la posiblidad real de que éstas hubieran sido puestas en práctica tal y como fueron planteadas en su momento- para desarrollar su propia concepción en torno a la escena, condicionada a su vez por un marcado interés hacia el cuerpo ${ }^{3}$. A pesar de que las ideas de Adolphe Appia en torno a la escena llegan incluso más allá de lo que él mismo se había

1 En las cuestiones planteadas por Victor Hugo, durante el primer tercio del siglo $\mathrm{XIX}$, en el prólogo a Cromwell, se resumen las bases de la teoría romántica en torno al teatro. Sus ideas, al igual que va a ocurrir con la teoría wagneriana, conllevan una paradoja por tratarse, por un lado, de «la entrega de la escena a las formas burguesas y abrir la senda que conducirá al realismo y al naturalismo» (Sánchez, 1999: 20) y por otro, por constituir al mismo tiempo, y en cierto sentido, el germen de la apertura de una vía que impulsará un giro en la escena teatral que supone, a su vez, su renovación, así como la revisión de la palabra como elemento fundamental y clave de la misma.

2 Son precisamente las ideas wagnerianas las que enlazan con el pensamiento de corte romántico, abriendo así la posibilidad de un cambio en el paradigma de la escena occidental a lo largo del siglo XX.

3 Este interés se encuentra en relación con el pensamiento en torno a la rítmica o euritmica que desarrolló Émile Jaques-Dalcroze, al que Adolphe Appia había conocido personalmente en 1906. 
propuesto en un principio, su pretensión primera consiste únicamente en asentar la teoría wagneriana en un planteamiento teórico, fundamentado, a su vez, en el propio conocimiento de la práctica escénica, así como en las necesidades del espacio físico en el que ésta se lleva a cabo. En su caso, la posibilidad sugerida de alcanzar un espectáculo total en el ámbito escénico le parece, en general, aunque no de un modo rotundo, válida; no tanto así el desarrollo y la realización práctica a la que había estado sujeta por haber carecido — según él-, desde el momento de su formulación como tal, de una reflexión teórica que la sustentase y que fuese capaz de plantear esa posibilidad desde los propios medios escénicos, es decir, sometiendo a observación detenida el modo en que éstos se relacionan entre sí.

La opinión de Edward Gordon Craig, respecto al músico alemán, es sustancialmente diferente a la de Adolphe Appia, puesto que Craig no se plantea, como sí lo hace Appia, la necesidad, ni el interés por llevar a escena las óperas wagnerianas, de acuerdo con los propios planteamientos de Wagner. No obstante, Gordon Craig, al comienzo de su texto teórico On the Art of Theatre, muestra un cierto interés por la posibilidad de que exista una cierta armonía entre los elementos escénicos, que incluso podríamos afirmar que guarda alguna conexión con las ideas del teórico suizo. Se refiere en concreto a la armonía entre los actores, armonía con el espacio escénico, así como armonía con las ideas del autor ${ }^{4}$ (Craig, 1957: 33). Sin embargo, a pesar de apuntar la posibilidad de que exista una cierta cohesión entre los elementos escénicos, posteriormente -en concreto a lo largo del fragmento sobre la übermarionette - no duda en afirmar de manera tajante que concibe imposible la unión de las artes (Craig, 1969: 44). Se limita Craig, al igual que el teórico y director de escena suizo ${ }^{5}$, a cuestionar

${ }^{4}$ La cuestión sobre la armonía con las ideas del autor resulta interesante por mostrar de algún modo hasta qué punto la «fidelidad» a la intención del autor queda incuestionada y es incuestionable, incluso en aquéllos que se plantean seriamente la legitimidad de las formas escénicas más tradicionales como poseedoras de la esencia teatral.

5 En su texto, La obra de arte viva o The Work of Living Art (trad. del original L'Oeuvre de "art vivant") Adolphe Appia afirma respecto a la idea de gesamtkunstwek lo siguiente: «such an idea is tempting - tempting because of the soothing simplification it so readily offers; and we have eagerly accepted this nonsense. [...] If dramatic art is to be merely a harmonious combination or union of all the other arts, then I no longer understand anything at all about any of them, and still less about dramatic art. Chaos is complete» (Appia, 1997: 5-6). («Una idea así es tentadora - tentadora por la tranquilizadora simplificación que tan fácilmente ofrece; y hemos aceptado gustosos este disparate. [...] Si el arte dramático tiene que ser una simple combinación armoniosa o unión del resto de las artes, entonces ya no entiendo nada en absoluto acerca de ninguna de ellas, y todavía menos sobre el arte dramático. El Caos es total». La traducción es mía). 
la idea central auspiciada en la teoría sobre la gesamtkunstwerk u obra de arte total. Como Appia, Gordon Craig expone sus dudas acerca de la operatividad práctica de tal idea, pero, dejando a un lado la posibilidad de reinterpretar las ideas wagnerianas desde sus mismas bases como lleva a cabo el teórico suizo, simplemente manifiesta serias dudas sobre la posibilidad de que en virtud de su reunión en un mismo espacio - en este caso la escena teatral-y prescindiendo de mediación temporal alguna, surja un arte autónomo a partir de aquéllas que lo conforman:

How can all arts combine and make one art? It can only make one joke... one theatre. Things which slowly, by a natural law join together, may have some right in the course of many years or many centuries to ask nature to bestow a new name on their product. Only by this means can a new art be born. [...] You cannot commingle them and cry out that you have created a new art $^{6}$ (Craig, 1969: 44).

Como decíamos, tomando como punto de partida este cuestionamiento, Adolphe Appia, sin embargo, ofrece una alternativa, o quizá mejor dicho una reflexión, que nos atrevemos a calificar de más profunda, incluso que la auspiciada por el propio Wagner. El teórico suizo se plantea las mismas cuestiones que el músico alemán aportando, no obstante, una alternativa al caso wagneriano -donde únicamente se consigue reunir palabra y música - y avanzando, de ese modo, una nueva teoría que sustente la tan buscada combinación de los distintos medios escénicos. De esta manera, al situar al cuerpo en el centro de la jerarquía propuesta, Appia da respuesta a la tendencia general -cuando menos en un sector del ámbito artístico- que comenzaba a cuestionar el papel de la palabra en el centro del espectáculo y empezaba a su vez a mostrar un interés por colocar al cuerpo en su lugar. En resumen, Adolphe Appia, probablemente debido a esa vinculación con las ideas del músico alemán, muestra una preocupación por el espectáculo como totalidad, que acaba traduciéndose en la entrada del cuerpo en su formulación de escena como elemento, en virtud del cual se hace posible el vínculo entre los distintos medios que se dan cita en la misma. No obstante, a pesar de su

6 « ¿Cómo pueden todas las artes combinarse y dar lugar a un único arte? Sólo puede dar lugar a una broma... a un teatro. Las cosas que pausadamente, mediante la ley natural se unen, pueden tener algún derecho para en el curso de los años o siglos pedirle a la naturaleza que le otorgue un nuevo nombre a su producto. Sólo así puede nacer un arte nuevo. (...) No se las puede poner juntas y proclamar que se ha creado un arte nuevo". La traducción es mía. 
preocupación por el lugar que ha de ocupar el cuerpo del actor en la escena, el teórico suizo no explora los terrenos de su papel en relación con un personaje, ni tampoco siente la necesidad de desarrollar un sistema de entrenamiento, como, sin embargo, sí intentarán hacer aquéllos a los que influye el magisterio de Stanislavski, así como, por supuesto, el propio teórico y director de escena ruso.

En todo caso, a pesar de la coincidencia en la actitud crítica hacia la posibilidad de llevar a cabo un espectáculo que surja como resultado de la combinación de las distintas artes, Adolphe Appia y Edward Gordon Craig se distinguen entre sí en una cuestión fundamental que, por otro lado, va a conducir a la idea de escena que cada uno de ellos propone: el primero, replantea la teoría wagneriana desde sus mismas bases; mientras que el segundo, se limita a criticarla, sin mostrar ningún interés por reformularla desde sus propios términos.

Por su parte Vsevolod Meyerhold, ya en los años veinte, opina que, si bien en un momento determinado las propuestas de Richard Wagner habían sido consideradas irrealizables e incluso disparatadas - como es el caso ya expuesto de Gordon Craig y el suyo propio años atrás (Meyerhold, 1968: 148)—, es la idea de espectáculo total la que finalmente debe subyacer a todos ellos:

\footnotetext{
Antes se consideraban utópicos los proyectos de Wagner de crear una especie de teatro sintético que, junto con los medios escénicos, utilizara, además de la palabra, la música y la luz, los movimientos rítmicos y toda la «magia» de las artes plásticas. Hoy vemos que así es justamente cómo hay que concebir los espectáculos (Ib.: 241).
}

Meyerhold se posiciona en cierto sentido de modo similar a Appia, ya que al igual que éste, la única objeción del teórico de la escena ruso a la gesamtkunstwerk viene dada por la necesidad de sustentar todo el planteamiento wagneriano en un conocimiento exhaustivo del modo en que se produce la relación entre las artes. En definitiva, con algunos años de diferencia, tanto Meyerhold como Appia - no así Gordon Craig - coinciden en la necesidad de profundizar en todo aquello que conlleva la propuesta enmarcada en el concepto de gesamtkunstwerk. Por lo que respecta al concepto en sí —gesamtkunstwerk-, es Adolphe Appia el único, de entre los cuatro teóricos que nos ocupan, que desarrolla una idea de escena elaborada sobre la propuesta de un modelo de relación entre sus componentes, a partir de una definición detallada de los mismos, así como de su papel individual en la escena. 
Por otra parte, los cuatro teóricos y directores de escena que nos ocupan pueden enmarcarse dentro de la tendencia artística que Ortega y Gasset denominó arte nuevo. En ese sentido podemos también afirmar que, en general, avanzan una propuesta escénica alejada de un tipo de representación cuyo criterio para su valoración sea su semejanza con la vida real, así como con la posibilidad de que el espectador se identifique completamente con las situaciones planteadas por el espectáculo.

Victor Hugo (1967: 35-6) había manifiestado el deseo de dar entrada en la escena a lo que él mismo denominaría ritmo de la naturaleza, que, como hemos señalado anteriormente, abría dos posibilidades de interpretación, que a su vez se traducían, por un lado, en una contribución desde las premisas románticas al asentamiento de Realismo y Naturalismo, y por otro, al igual que ocurría con la posibilidad auspiciada por Wagner, en una comprensión de la escena como un todo orgánico sin límites entre sus componentes.

En general, de un modo u otro, tanto Appia como Craig, Stanislavski y Meyerhold conciben la escena como entidad autónoma que con sus medios propios, y aun teniendo como referente la vida real, no conduzca, sin embargo, a un abandono de la misma como espacio para su reproducción. En definitiva, manifiestan incluido el propio Stanislavski, un deseo de distanciamiento de lo que constituía la escena decimonónica que se traduce además en un interés por entender ésta - la escena- de modo autónomo, de manera que, sin convertirse en un mero reflejo de ella, funcione como lo hace la naturaleza, es decir, como un organismo independiente que se rige por sus propias leyes.

Sus respectivas respuestas a esta cuestión se fundamentan en sus diversos puntos de vista a la hora de definir y llevar a cabo sus propios espectáculos y se van a traducir, a su vez, en distintos modos de entender el papel del actor en la misma. Para Adolphe Appia es el actor el que surge como único elemento capaz de llevar el componente orgánico a la escena y hacerla funcionar como tal. Gordon Craig, por su parte, decide prescindir de su presencia por considerarlo un obstáculo para su concepción escénica, mientras que para Constantin Stanislavski el actor tiene como cometido desarrollar una técnica que lo proteja de la eventualidad y subraye su trabajo sobre el personaje como elemento de un universo que ya no es reflejo de nada. No se trata entonces — puntualiza Stanislavski- de reflejar la realidad desde la escena, sino de crear una que sea autónoma, sin renunciar por ello a la vida real como referente. A su vez, Meyerhold se muestra interesado 
en las posibilidades que el trabajo sobre la técnica actoral abre para la escena y considera que ésta no puede tener ni tiene como propósito la simple reproducción de la vida. Su idea de espectáculo queda entonces centrada en la búsqueda de medios escénicos que la evoquen, sin llegar a reflejarla fielmente y sin proyectar sobre el espectador un ilusionismo falaz.

De entre todos, Adolphe Appia es probablemente el caso que se aproxima más a entender la escena como si de un organismo vivo se tratase, así como a poner en práctica la idea de espectáculo orgánico que formulase Hugo. Alrededor de ese concepto se centra fundamentalmente el pensamiento desarrollado en L'Ouvre d'art vivant, cuyas conclusiones se circunscriben al cuerpo del actor como elemento, en virtud del cual se puede llevar a cabo esa unión planteada a partir del elemento vital. El espectáculo teatral se constituye en obra de arte viva, precisamente por la presencia, a su vez, del cuerpo vivo del actor. Surge entonces éste como centro y unión del resto de los elementos que entran a formar parte de la escena, y de tal modo el ritmo de la vida - lo orgánico-, precisamente conducido por la presencia de la entidad corporal — sin necesidad de que el espectáculo teatral trate de ser un reflejo fiel y casi fotográfico de la realidad-, hace su entrada en escena.

Edward Gordon Craig, por su parte, se refiere igualmente a la naturaleza - su fuente de inspiración, dirá él-y se manifiesta, como todos ellos, incluido el propio Stanislavski, en contra de la reproducción exacta y fotográfica de la realidad en el ámbito de la escena, que, en consecuencia, ha de entenderse como espacio autónomo. En el caso de Craig se hace además necesario eliminar la figura del actor -cuya presencia para el teórico británico va íntimamente ligada a los modos realistas y naturalistas de representación teatral- por no encajar con su concepción de escena. El deseo de Gordon Craig es poner en práctica un modo de entender el teatro, en el que se excluye por completo la posibilidad de reflejar o incluso evocar remotamente la realidad sobre la escena teatral, para lo cual considera imprescindible no sólo acabar con la figura del actor, a la que vincula precisamente con la probabilidad de ilusionismo que se plantea desde el escenario, sino erradicar toda posibilidad de identificación por parte del espectador con aquello que presencia sobre el mismo:

Do away with the actor, and you do away with the means by which a debased stage realism is produced and flourishes. No longer would there be a 
living figure to confuse us into connecting actuality and art; no longer a living figure in which the weakness and tremors of the flesh were perceptible $^{7}$ (Craig, 1969, 49).

En todo caso, a pesar de que su concepto de escena no va encaminado a tener al actor como centro, hemos de subrayar el hecho de que sobre el escenario mantiene una figura que funciona como lo haría el cuerpo si éste pudiera deshacerse de sus ataduras, respecto a ese determinado modo de actuación que Craig precisamente asocia con su presencia. Prescinde el director de escena y teórico británico, por tanto, del elemento vital, ya que, en su opinión, la vida aportada por la presencia del cuerpo del actor en la escena no resulta en ningun caso significativa.

La solución propuesta por Stanislavski para dar entrada a la naturaleza en el espectáculo no se distancia de los modos de representación fundamentalmente realistas, aunque procura llevar a cabo una profundización mayor sobre los medios que esta clase de puesta en escena tiende a poner en juego. De igual modo ocurre con el actor, para el que, a diferencia de lo que se estaba llevando a cabo en la escena teatral de ese momento, sobre todo centrada en las denominadas formas dramáticas tradicionales burguesas, no propone nada nuevo, excepto ahondar en las posibilidades que la dramaturgia actoral tradicional ofrece. En cualquier caso, no hay que obviar el hecho de que Constantin Stanislavski no cuestiona la dramaturgia resultante de la lectura aristotélica hecha por la Ilustración y el siglo XVIII, lo que, por otro lado, no elimina la necesidad de atender al aspecto físico del actor en su totalidad, cuestión que, sin embargo, sí es pasada por alto por las formas de representación burguesas, centradas, en lo que respecta al aspecto físico del actor, en el ámbito concreto de la boca. En su caso, la naturaleza hace acto de presencia en virtud del hecho de que el actor no representa ${ }^{8}$ nada, sino que actúa desde dentro de las emociones, pasiones e imágenes de un papel.

Por su parte, a pesar de su oposición al naturalismo escénico concentrado para él en la persona de Stanislavski, la pretensión de

7 «Acaba con el actor, y acabarás con los medios mediante los cuales un degradado realismo escénico se produce y florece. No existirá nunca más una figura viva para confundirnos al conectar realidad y arte; nunca más una figura viva en la que las debilidades y temblores de la carne sean perceptibles». La traducción de este fragmento es mía.

8 Entendiendo representación como reproducción externa de la realidad. 
Meyerhold, en un principio, no es distanciarse de manera radical de un modo de representación fundamentalmente realista. No obstante, su intención es tratar la realidad de manera diferente, de tal modo que el espectador sea consciente de que, entre otras cosas, se halla ante una forma de presentar la vida, conformada de manera diferente y con unos fines muy diversos:

\begin{abstract}
En el ámbito del teatro convencional somos profundamente realistas, y podéis encontrar en la vida al hombre que nosotros presentamos [...] de cuanto percibimos elegimos siempre lo más típico [...]) los enlazamos entre sí de manera que las finalidades que nos proponemos se realicen de forma condensada [...] que se note la mano de un maestro, la mano del artista (Meyerhold, 1968: 259-60).
\end{abstract}

A su vez, todas estas cuestiones conducen hacia un concepto de escena en el que, de un modo u otro, el cuerpo surge como elemento central y relacionado asimismo con otro concepto, el de movimiento, y ambos a su vez con la presencia o ausencia de vida en la escena. Los cuatro teóricos y directores de escena que nos ocupan se encuentran reflexionando sobre el ámbito escénico del momento y en sus respuestas aparece, por un lado, la necesidad de resituar el cuerpo en la misma, y por otro, la posibilidad de definición de lo que denominan movimiento, que toma distintas formas, según el teórico, y -ya dentro del ámbito de las ideas de cada uno- en función de su relación con la presencia de lo corporal en la escena teatral.

Tanto Adolphe Appia como Gordon Craig se ocupan de tratar la cuestión en torno al movimiento: el primero, lo relacionará con el cuerpo vivo, considerando así no sólo que movimiento y vida son la misma cosa — «Movement, that is to say Life» (Appia, 1997: 80)_, sino que éste, es decir, el movimiento, es en definitiva el elemento que vincula música y escenografía a través del cuerpo. Gordon Craig lleva a cabo una definición más intrincada del mismo, en la que señala que éste es el origen de todo, el origen del teatro en definitiva. Si el movimiento fuese mecánico se podría entonces concebir la posibilidad de fijar los elementos constituyentes del mismo, lo que para Appia supondría el sacrificio y la renuncia al arte (Appia, 1997, 32); renuncia que, sin embargo, en el entorno de las ideas formuladas por Craig, se produce precisamente cuando en la escena aparece un cuerpo vivo. El teórico británico considera que, en virtud de la presencia del actor vivo sobre el escenario, el teatro, que podría ser considerado un arte, no lo sea. Por el contrario, cuerpo y movimiento son para Appia conceptos cen- 
trales por su capacidad de situar la vida ${ }^{9}$ en la escena, en virtud de ese hecho hacerla viva y conseguir en último lugar poner en relación, no sin antes establecer una cierta jerarquía, al resto de elementos escénicos. Renunciar a la vida, al cuerpo, en definitiva al movimiento que éste ejerce en la escena, es renunciar, según Appia, al arte mismo. Craig, sin embargo, considera que al arte únicamente se llega si ejercemos esa — para él-absolutamente necesaria renuncia.

Quizá pudiésemos decir entonces que, si bien los dos teóricos colocan al movimiento en el centro de sus preocupaciones, la diferencia fundamental entre ambos reside en la figura que lo ejecuta. Appia opta por la vida en detrimento de la perfección; Craig, por su parte, renuncia al cuerpo vivo por considerarlo corruptor de la escena y, en su lugar, coloca un artefacto - übermarionette - sin vida - a no ser la que le otorga el director de escena - que, en última instancia, no deja de ser también un cuerpo sobre el escenario. No obstante, la presencia en escena de una figura que guarda ciertas similitudes con el cuerpo del actor, abre nuevas posibilidades para definir, desde instancias muy diferentes a las meramente psicológicas de aproximación al drama, los propios conceptos de actor y cuerpo. No en vano el movimiento, dice Craig, surge de la danza, es decir, supuestamente de un cuerpo humano danzando. Más allá incluso de esta afirmación, al plantear la cuestión en torno al origen del teatro, apunta que el gesto probablemente sea el elemento más importante de la escena. En definitiva, dejando a un lado el hecho concreto de que el actor contemporáneo no se encuentre, desde su personal punto de vista, preparado para ello, el cuerpo del actor sería determinante en última instancia de la escena teatral.

Stanislavski, sin embargo, no cree en la posibilidad de llevar a la escena el movimiento aislado de la presencia de la palabra o de una idea que lo sustente y lo justifique. De todos modos, es importante subrayar que para él la presencia del gesto corporal en escena es crucial, en última instancia y en todos los casos, por enteder que éste actúa como portador y transmisor de aquello que la misma palabra no sabe o simplemente no puede transmitir. En relación con esta cuestión se va a referir el teórico ruso a la vida —en parte de manera similar a como ya lo había hecho Appia-, aunque con las diferencias que conlleva el hecho de que el concepto de vida que manejan ambos no sea

9 El elemento vital, la vida en definitiva para Appia es considerada un valor positivo. 
en todo momento el mismo. Si bien al segundo le preocupa que haya un elemento vivo sobre el escenario, en virtud de la presencia de un cuerpo - no necesariamente de un personaje-, en el caso de Stanislavski el elemento vital proviene de la capacidad del actor a la hora de construir un personaje, de dejar que su naturaleza opere de manera controlada sobre la escena, en concreto a través de su sistema, y de tal modo conseguir que ésta funcione con las mismas reglas que lo hace aquélla, es decir, la naturaleza.

Por otro lado, en relación con el modo en que se había expresado Gordon Craig ${ }^{10}$, Meyerhold considera que este movimiento no se ha de reducir al ejecutado por el cuerpo, sino que debe afectar a todo aquello que se traslada y se dispone de un modo particular en el espacio escénico:

El movimiento en la escena no viene dado por el movimiento en el sentido literal de la palabra, sino por la distribución de las líneas y colores, y por la facilidad y maestría con que líneas y colores se entrelazan y vibran (Meyerhold, 1999: 290).

El movimiento, por tanto, se haya vinculado en los cuatro teóricos a aquella instancia corporal, viva o no, que se convierte de un modo u otro en centro de su concepción de escena. A pesar de las diferencias en cuanto al modelo de escena que todos ellos proponen, en general podemos afirmar que los cuatro llegan a una misma conclusión final, es decir, el movimiento es la instancia que puede expresar lo oculto, aquello que pertenece al ámbito de los sentimientos del autor ${ }^{11}$ y se ha demostrado inexpresable mediante el lenguaje natural. A pesar de tener en cuenta el hecho de que el movimiento transciende el propio cuerpo que lo ejecuta, éste-el cuerpo-surge en definitiva como traductor de sentimientos, como elemento, en definitiva, con una gran capacidad de evocación simbólica. Así, movimiento y cuerpo quedan definidos como elementos sustitutorios de la palabra en la escena -incluso cuando no se prescinda de ella en el espectáculo- a la hora de

10 El movimiento es para Gordon Craig, equiparable a aquellos otros elementos que desde la escena desafiaban la capacidad racional que se había ocupado de abanderar y explotar el texto dramático o, en definitiva, la palabra. Se asocia a la música, a la luz y a todos aquellos elementos que cuestionan la posibilidad de otorgar, a lo que ocurre en la escena, un significado directo y comprensible por la razón del espectador.

11 Entendiendo autor en este caso no como autor dramático, sino como director o, en definitiva, mente rectora y responsable del espectáculo como un todo. 
evocar los sentimientos del alma ${ }^{12}$. El movimiento aparece, por tanto, relacionado con la vida y ésta asociada, a su vez, con la presencia del actor en la escena o incluso con la necesidad, como ocurre en el caso de Gordon Craig, de prescindir de esa instancia.

El interés de Craig en la übermarionette guarda ciertos vínculos con una tendencia casi contemporánea que se manifiesta a favor de un teatro no sin cuerpo, pero sí sin vida, al que había conducido el interés -inaugurado por Kleist - por la marioneta como entidad «con toda la apariencia de vida pero sin vida» ${ }^{13}$, característica que lograría potenciar - según los simbolistas- su capacidad para expresar la idea que, según éstos, se encuentra detrás de lo que aparentemente se está mostrando. Es entonces Craig el que probablemente se aproxime más a la idea de deshumanización del arte planteada por Ortega:

Sin duda el títere demuestra que no tiene necesidad de la verdad exterior; de la apariencia para convencer al espectador de la verdad espiritual interior (Braun, 1986: 51).

La übermarionette concentra en sí misma la capacidad que, para desrealizar el arte y en concreto en este caso la escena, Ortega atribuye a la metáfora a la hora de referirse al arte nuevo:

La metáfora es probablemente la potencia más fértil que el hombre posee. [...] es verdaderamente extraña la existencia en el hombre de esta actividad mental que consiste en suplantar una cosa por otra, no tanto por afán de llegar a ésta como por rehuir aquella. La metáfora escamotea un objeto enmascarándolo con otro, y no tendría sentido si no viéramos bajo ella un instinto que induce al hombre a evitar realidades (Ortega y Gasset, 1960: 32-3).

Gordon Craig, al igual que Appia, centra su interés precisamente en la instancia, más o menos humana, que domina la escena, a pesar de que no desee que, en un principio, se trate de un cuerpo vivo, por todas

12 La cuestión en torno al alma hace a los cuatro de un modo u otro partícipes de las bases que fundamentan la teoría romántica del arte. En definitiva los cuatro teóricos que nos ocupan participan de esta idea y la reproducen desde un concepto sobre el teatro fundamentado sobre la premisas simbolistas que no en vano tienen una vinculación importante con las románticas.

13 Maeterlinck. Citado en Braun, 1986: 51. 
las desventajas que lleva consigo. En consecuencia, vinculándose así a toda la tradición finisecular que volvía su mirada hacia las marionetas, se ocupa de concebir una figura - la übermarionette - para la escena que se pliegue a los deseos del director y que, a la vez, permanezca ajena a sus propias emociones y deseos particulares. Appia, sin embargo, discrepa respecto al uso de la marioneta, precisamente por entender la escena de manera diferente. El teórico suizo concibe la escena como lugar donde se desarrolla un espectáculo que está vivo, precisamente por la presencia del cuerpo, vivo, que aparece en escena y que actúa como vínculo mediante el cual el resto de los elementos que allí se dan cita pueden entrar en relación. En virtud de su presencia toman la cualidad de la vida, de modo que se hará posible entonces hablar igualmente de espacio y tiempo vivos:

The only thing to do is to begin again at the beginning - that is to say, with the primordial elements. The living presence of the body will create living Space and Time, and the incorporation of music into this body will effect that aesthetic modification which is the peculiar property of a work of $\operatorname{art}^{14}$ (1997: 55).

Craig, sin embargo, piensa la escena desde un lugar diferente. Conoce bien el sistema de estrellas imperante en la escena teatral de finales del siglo XIX, contra el que se rebela, expresando en ese contexto su deseo de acabar con la figura del actor. No obstante, como hemos venido apuntando, se decanta por una instancia que, aunque guarda una cierta relación con aquella con la que quiere acabar, es capaz de amoldarse completamente a los deseos del director. Incluso el propio Meyerhold justifica la actitud de Gordon Craig respecto al actor señalando que,

si Craig afirma que «la interpretación del actor no es un arte», hay que comprender que habla sólo de los sistemas anárquicos, de la ausencia en los actores de los últimos veinte años de cualquier tipo de preocupación por la necesidad de poner el propio material en las condiciones de un cálculo exacto (Meyerhold, 1968: 200).

14 «La única cosa por hacer es comenzar de nuevo por el principio —es decir, con los elementos primordiales. La presencia viva del cuerpo creará Espacio y Tiempo vivos, y la incorporación de la música dentro de este cuerpo tendrá como efecto que esa modificación estética que es la propiedad peculiar de la obra de arte». La traducción de este fragmento es mía. 
Su deseo de llegar a un arte perfecto - de ahí la necesidad de la übermarionette - guarda, a su vez, una cierta relación con las ideas de Isadora Duncan en torno a la unión de danza y religión, sin la cual la danza no alcanza a ser arte sino entretenimiento y mercancía. Piensa Appia, por el contrario, que intentar llevar a cabo un espectáculo mecánico, perfecto, es, sin lugar a dudas, acabar con el arte, porque se acaba con la vida que, para él, constituye en ese sentido su elemento más específico.

En la Introducción a su volumen sobre Meyerhold -Meyerhold, Eisenstein and Biomechanics. Actor Training in Revolutionary Russia - Gordon y Law apuntan que la expresión vivir el personaje no es entendida de igual modo por Stanislavski y por Meyerhold. Para el primero, consiste en la fusión total del actor con su personaje, de manera que el actor pasa de un plano de realidad a otro en el que entra en otra vida; mientras que para Meyerhold el actor no debe olvidar que se halla en un escenario y que frente a él se encuentra el público ${ }^{15}$. En su caso el actor nunca se abandona en esa otra vida a la que se refería su maestro:

For Meyerhold «feeling» was strictly a technical term having to do with helping the actor to find positions and movements that were not only expressive, but also ones he could live with. Meyerhold always knew exactly what effect he wanted his actors to achieve ${ }^{16}$ (Law y Gordon, 1996: 96).

A diferencia de Craig, que, como veíamos, estaba interesado por un espectáculo teatral que prescindiese de la vida, ya que relaciona íntimamente ésta y espectáculo realista y por tanto aboga por la übermarionette como exponente de un espectáculo con cuerpo pero sin vida, Stanislavski, al igual que Appia, parece más interesado —quizá en esa línea realista respecto a la cual Craig quiere distanciarse- por la vida sobre el escenario. No obstante, mientras que a éste la vida que Adolphe Appia desea para la escena viene proporcionada por el mero

15 Es destacable en este sentido que cuando Meyerhold se refiere a la fórmula que resume la actividad del actor- $\mathrm{N}=\mathrm{A} 1+\mathrm{A} 2$-no utiliza el término artista, sino que habla de aquel que organiza el material, o constructor, y del propio material.

16 «Para Meyerhold "sentir" era un término estrictamente técnico que tenía que ver con la asistencia al actor a encontrar posturas y movimientos que fueran no sólo expresivas, sino que uno pudiera vivir con ellas, Meyerhold siempre supo qué efecto quería que sus actores alcanzasen». La traducción es mía. 
hecho de que aparezca un cuerpo sobre el escenario, en el caso de Stanislavski es una vida que ha de encontrarse ligada de algún modo a la vida real de una persona ${ }^{17}$. Es por tanto la aparición de una personalidad individual —con todos sus atributos físicos desde luego, pero una psicología al fin y al cabo- sobre el escenario la que va a proporcionar la vida buscada para la escena ${ }^{18}$.

Para concluir, podemos recordar que ambos, Adolphe Appia y Edward Gordon Craig, compartían un mismo interés por plantear un espectáculo que sobrepasase las barreras trazadas por el Realismo y el Naturalismo en sus manifestaciones más banales y se enfrentase a la posibilidad de mostrar lo oculto - aquello que reside en el alma-, que en ambos casos se localiza asociado al movimiento: para Appia desempeñado por un cuerpo vivo, o en el caso de Craig, por un elemento sustitutivo del cuerpo humano - la übermarionette-, dotado de características místicas y casi mágicas.

Sin embargo, no son sólo estos dos teóricos y hombres de escena los que van a plantear esta cuestión, sino que el propio Constantin Stanislavski, desde un modo de entender la escena no obstante mucho más vinculada al Realismo y al Naturalismo, y con una concepción de la misma mucho más tradicional y sin pretensiones de reforma fuera de la propia tradición realista a la que nos referíamos, recurre al movimiento corporal como uno de los fundamentos de sus teorías en torno a la preparación del actor, además de como medio que permite a éste mismo - al actor- expresar sobre la escena los sentimientos del alma -interés y preocupación que también forman parte de sus escritos teóricos y espectáculos teatrales-.

Que Meyerhold, desde que dejase el Teatro de Arte e incluso a través de su colaboración con el mismo a través del Teatro-Estudio, manifestase abierta y radicalmente su deseo de proporcionar para la escena una alternativa a la propuesta stanislavskiana, y el hecho de que nosotros mismos veamos una posible conexión entre ambos, nos podría hacer pensar o bien que las ideas de Stanislavski no están en

17 El teórico y director de escena ruso en una de las secciones dedicadas a la descripción del trabajo con los actores, comenta sobre dos de los personajes que sus alumnos acababan de mostrar al resto, que ambos podían ser calificados como generalizaciones, ya que para él no había vida en esas caracterizaciones por parecer figuras de un ritual (Stanislavski, 1999: 27).

18 A su vez, su propio concepto de vida en la escena está relacionado con la propia idea que sustenta su sistema, y para lo cual lo ha ideado, es decir, para que la escena en definitiva funcione como lo hace la naturaleza. 
último término tan separadas de las de los otros tres teóricos - sin embargo mucho más facilmente conectadas entre sí- o bien que la cuestión se resume en último término en el hecho de que todos ellos comparten, como reformadores de la escena decimonónica europea con la que se habían encontrado, un mismo interés, es decir, encontrar un medio de llevar a escena lo que todos, de un modo u otro, denominan el alma del artista, el alma del drama teatral, al que se aproximan aventurando diversas tentativas de espectáculo entre cuyos bastidores yace la misma preocupación compartida: ¿qué puede convertirse en portador de aquello que las palabras del texto dramático por sí solas no pueden expresar?

Probablemente, entonces, podamos considerar a Meyerhold el último eslabón de una cadena dentro de las tendencias que tienden a mirar de nuevo al cuerpo del actor como alternativa a un teatro en el que la palabra y el texto dramático se habían convertido en el centro en torno al cual el espectáculo quedaba configurado.

Como ya veíamos en el caso de Adolphe Appia, el movimiento, íntimamente vinculado al cuerpo del actor o del bailarín, está además unido a la misma música con quien comparte, siempre a través de la instancia corporal, la característica de ser capaz de expresar, frente a la palabra, los sentimientos del artista. En la concepción del teórico suizo la música y el cuerpo - portador indiscutible del movimiento- se necesitan mutuamente: la música requiere la presencia del cuerpo para encontrar expresión física y espacial de lo que no es, en definitiva, para Appia más que tiempo, del mismo modo que el cuerpo necesita regirse por la música - por el ritmo temporal, en definitiva - para ser capaz de convertirse, a su vez, en portador físico de los sentimientos contenidos en aquélla. El cuerpo se eleva entonces como elemento dominante en la escena, aunque como instancia dependiente de la música, sin la cual no podría llevar a cabo su cometido, es decir, expresar lo profundo, los sentimientos del alma de los que, a su vez, se considera que la música es portadora y, en suma, la que puede procurar al cuerpo la asistencia requerida en esa tarea. En el caso de Gordon Craig los términos quedan invertidos, pues si bien para Appia el cuerpo es el único en virtud del cual se puede concebir el espectáculo, y la música todavía ejerce un papel determinante sobre éste, para el teórico británico todos los elementos que se dan cita en la puesta en escena están no sólo supeditados al movimiento, sino que surgen del mismo.

En el caso de Stanislavski resulta relevante la importancia que se le otorga al cuerpo, sobre todo en relación con la caracterización interna 
del personaje y como instrumento que consigue dar forma externa a sentimientos invisibles. Meyerhold, sin embargo, separándose de Stanislavski, con el que había comenzado trabajando en el Teatro de Arte, tras rebelarse contra la interpretación actoral reducida a la palabra y la gesticulación facial, considera necesario encontar nuevos medios para desvelar lo oculto. Opta, entonces, por la biomecánica que implica, por un lado, un dominio del cuerpo por parte del actor y, por otro, otorgar a cada movimiento una motivación coherente con aquélla que rige todo el espectáculo.

En definitiva, la tendencia que empezábamos a desgranar con Adolphe Appia — cuyo énfasis sobre el cuerpo es total-, continuábamos con Edward Gordon Craig - que propone acabar con la presencia del cuerpo vivo, en cuyo lugar aparece un artefacto con muchos de los atributos corporales, excepto la posibilidad de que sus pasiones y sentimientos acaben con el trabajo físico del mismo en un sólo instante de debilidad-, seguíamos con Constantin Stanislavski -cuya atención al dominio físico del cuerpo va unida al propósito de establecer las bases tanto físicas como psicológicas del personaje-, quizá pueda culminar con Vesevolod Meyerhold, cuya teoría biomecánica podríamos calificar de intento por restaurar el cuerpo del actor en la escena, tras haber pasado ésta por la necesaria übermarionette craigniana.

\section{Referencias bibliográficas}

APPIA, Adolphe (1997). The Work of Living Art \& Man Is the Measure of All Things, Barnard Hewitt (ed. y trad.). Coral Gables, Florida: University of Miami Press.

ARTAUD, Antonin (1986). El teatro y su doble. Barcelona: Edhasa.

BRAUn, Edward (1986). El director y la escena. Del naturalismo a Grotowski. Buenos Aires: Galerna.

CraIG, Edward G. (1957). Del arte del teatro. Argentina: Hachette.

- (1969). «The Actor and the Übermarionette». En Total Theatre. A Critical Anthology, E. T. Kirby (ed.), 33-57. New York: E. P. Dutton \& Co.

Grande Rosales, M. á Ángeles y Sánchez Trigueros, Antonio (1996). «Teatro, drama, espectáculo». En Manual de teoría de la literatura, J. A. Hernández Guerrero (coord.), 257-270. Sevilla: Algaida.

Hugo, Victor (1967). «Prefacio». En Cromwell, 11-51. Madrid: Austral. 
LAw, Alma, H. y GoRdon, Mel (1996). Meyerhold, Eisenstein and Biomechanics: Actor Training in Revolutionary Russia. Jefferson, N.C.: McFarland.

MEYERHOLD, Vsevolod (1968). Meyerhold. Textos teóricos. Volumen 1, J. A. Hormigón (introd. y selec.). Madrid: Comunicación.

- (1999). «El teatro de la Convención». En La escena moderna. Manifiestos y textos sobre teatro de la época de las vanguardias, J. A. Sánchez (ed.), 285-290. Madrid: Akal.

ORTEGA y GASSET, José (1960). La deshumanización del arte. Madrid: Revista de Occidente.

SÁnCHEZ, José Antonio (1999). Dramaturgias de la imagen, 2. ed. Cuenca: Universidad de Castilla-La Mancha.

StANISLAVSKI, Constantin (1999). Building a Character. London: Methuen. 